\title{
A Sensitive Impedimetric Sensor Based on Biosourced Polyphosphine Films for the Detection of Lead Ions
}

\author{
Taha Chabbah ${ }^{1,2}{ }^{\oplus}$, Houyem Abderrazak ${ }^{1}$, Radhia Souissi ${ }^{1}$, Patrice Saint-Martin ${ }^{3}$, \\ Herve Casabianca ${ }^{3}$, Saber Chatti ${ }^{1}$, Regis Mercier ${ }^{4}$, Ilhem Rassas ${ }^{3}$, Abdelhamid Errachid $^{3}$, \\ Mohamed Hammami ${ }^{1}$ and Nicole Jaffrezic-Renault ${ }^{3, *}$ (D) \\ 1 National Institute of Research and Physicochemical Analysis (INRAP), Biotechnopole of Sidi Thabet, \\ 2020 Ariana, Tunisia; taha.chabbah@fst.utm.tn (T.C.); houyem.snani@yahoo.fr (H.A.); \\ souissiradhia@yahoo.fr (R.S.); saberchatti2014@gmail.com (S.C.); mohamed.hammami@inrap.rnrt.tn (M.H.) \\ 2 Faculty of Sciences, University of Tunis El Manar, Farhat Hached Universitary Campus, 1068 Tunis, Tunisia \\ 3 Institute of Analytical Sciences, University of Lyon, UMR 5280, 5 Rue de la Doua, 69100 Villeurbanne, France; \\ patrice.saint-martin@isa-lyon.fr (P.S.-M.); herve.casabianca@isa-lyon.fr (H.C.); ilhemras@hotmail.fr (I.R.); \\ abdelhamid.errachid-el-salhi@univ-lyon1.fr (A.E.) \\ 4 Institute of Polymer Materials, University of Lyon, UMR 5223, 5 Rue V. Grignard, \\ 69622 Villeurbanne CEDEX, France; regis.mercier@univ-lyon1.fr \\ * Correspondence: nicole.jaffrezic@univ-lyon1.fr
}

Received: 3 April 2020; Accepted: 9 May 2020; Published: 11 May 2020

\begin{abstract}
In this work, impedimetric sensors were developed for the detection of the four WFD heavy metals $\mathrm{Pb}^{2+}, \mathrm{Cd}^{2+}, \mathrm{Hg}^{2+}$ and $\mathrm{Ni}^{2+}$, by the modification of a gold electrode with four partially biosourced polyphosphine polymers. These polymers were obtained with satisfactory yields by polycondensation of the bis(4-fluorophenyl)(4-methylphenyl)phosphine sulfide and the bis(4-fluorophenyl)(4-methylphenyl)phosphine oxide using isosorbide or bisphenol A. The chemical structures and number-average molecular weights of the resulting polymers were determined by NMR spectroscopy $\left({ }^{1} \mathrm{H},{ }^{19} \mathrm{~F}\right.$, and $\left.{ }^{31} \mathrm{P}\right)$ and by size exclusion chromatography. Glass transition temperatures varied between 184 and $202^{\circ} \mathrm{C}$ depending on the composition of polymers. The bio-based poly(etherphosphine) oxide modified sensor showed better analytical performance than petrochemical based oxide for the detection of $\mathrm{Pb}^{2+}$. A detection limit of $10^{-10} \mathrm{~g} / \mathrm{L}$ or $0.5 \mathrm{pM}$, which is $10^{4}$ times lower than that of the anodic stripping voltammetric and the potentiometric sensors. A reversibility is obtained through rinsing of the impedimetric sensor with an EDTA solution.
\end{abstract}

Keywords: biobased polyphosphine films; gold electrodes; electrochemical impedance spectroscopy; lead ions

\section{Introduction}

Heavy metals occur in the environment coming from industry effluents and emissions, fertilizers, mining and household wastes [1-3]. These micropollutants do not decompose and have a tendency to accumulate in the human body when ingested, causing various diseases and disorders to the nervous, immune, liver, skin, reproductive and gastrointestinal systems [4-7]. The Water Framework Directive (WFD) that governs European water policy cites four metals: lead, cadmium, nickel and mercury. The WFD has been placed as the main European regulation for the protection of the water resources [8]. One of its principal objectives is to achieve good chemical and ecological status and to restore and to preserve water bodies at a "good status". Chemical status refers to specific pollutants (e.g., priority substances or priority hazardous substances) and environmental quality standards (EQS) are defined for them. Environmental Quality Standards (EQS) for $\mathrm{Cd}, \mathrm{Ni}, \mathrm{Pb}$, and $\mathrm{Hg}$ are, respectively, 0.7-2.2, 341,35 , and $0.25 \mathrm{nM}$. As the WFD implementation gradually comes into effect in European countries, 
the environmental metrology market is bound to increase over the coming years. Consequently, faced with this metrological challenge and the urgency of the situation, a paradigm shift is required in order to imagine a new approach to the problem of water monitoring.

Atomic absorption spectroscopy (AAS) [9], X-ray fluorescence spectrometry (XRF) [10], inductively coupled plasma mass spectroscopy (ICP-MS) [11], neutron activation analysis (NAA) [12] and inductively coupled plasma-optical emission spectrometry (ICP-OES) [13], are the main techniques reported for the sensitive detection of heavy metals. However, these laboratory methods need expensive equipment, multi-step sample preparation and are not easy to use and require trained professionals. Electrochemical sensors based on a low cost and portative instrumentation are good candidates for the on-field detection of heavy metal ions. The flagship technique is the anodic stripping voltammetry, using alternative materials to mercury, such as boron-doped diamond [14,15]. This technique allows the simultaneous detection of WFD metallic ions and their detection limits are in the range of $\mathrm{nM}$, quite compatible with the WFD requirements. The main problems related to this technique is the reusability of the electrode because the reduced deposited metal should be removed with aggressive solutions, not compatible with their on-field use. For the development of selective and sensitive chemical sensors, the design of selective metals-interacting assembled units is required in order to constitute the recognition layers at the surface of the electrochemical devices. Oxygen, sulfur, phosphorus and nitrogen heteroatoms allow the complexation of the metal cations according to their hardness or softness on the HSAB scale. These specific complexing groups being attached to the electrode through low or high molecular weight organic molecules, the surface complexation of the metal ions is detected through potentiometry [16] or voltammetry [17] or impedancemetry [18]. Molecules wearing phosphine groups were used particularly as ionophores for the detection of metals. Trioctylphosphine oxide was used for the impedimetric detection of chromium [19]. Phosphorylated hexahomotrioxacalix [3] arene was used for the potentiometric detection of lead [20]. In both cases, the molecules were inserted in a polymeric matrix such as polysiloxane or polyvinylchloride, then limiting the shelf lifetime of the sensor, due to the leakage of the ionophore molecule. Electrochemical sensors generally give detection limits in the range of nM or less, which is quite compatible with the requirements of the WFD. The main drawback is the reusability of these sensors. In this work, we propose phosphorus polymer-modified gold electrodes for the impedimetric detection of the WFD metallic ions. The phosphine groups are known to have affinity for metals and in the polymer chain, these groups will be numerous, stable and easily accessible. The sensor structure will then be robust for a long shelf lifetime.

Phosphorous polymers can be used as fire retardants, flame proofers, surface adhesion reagents, catalysts and tooth preservers [21-25]. To the best of our knowledge, no attempts have been made to use phosphorus polymers as films for electrode modification, for sensor application. In this aim, two phosphorus containing polymers, poly(arylene ether phosphine oxide)s and poly(arylene ether phosphine sulfide)s were synthesized in order to be used as films for the modification of gold electrode for the sensitive detection of heavy metals in water. The synthetic pathways adopted to produce the phosphorus containing polymers is the nucleophilic aromatic substitution of the two prepared difluor aromatics, phosphine sulfide and phosphine oxide monomers, with a petrochemical based aromatic monomer or a bio-derived cyclic monomer. The petro-based chosen monomer is the bisphenol-A (BPA), the key diol monomer for improving the mechanical and thermal properties of engineering plastics due to its heavy, rigid and distorted molecular structure [26-29]. For the bio-based monomer, we used the 1,4:3,6-dianhydro-D-glucitol, known as isosorbide (ISB) and particularly the unique bicyclic dianhydroalditol, commercially available to date. It was extensively used as monomer for the synthesis of numerous polymers [30-34]. It is an important bio-based diol monomer rigid suitable for the elaboration of heat-stable polymeric block and is one of the alternative candidates for replacing BPA [35-38]. ISB cannot only improve the mechanical properties of the incorporated polymer, but also possesses good optical and UV-resistive properties due to its unique molecular structure [36-38]. Moreover, the non-toxicity of ISB has been proven and it has been widely used in pharmaceuticals and cosmetics $[39,40]$. The use of isosorbide as raw material for plastics can address environmental 
issues like reduction in $\mathrm{CO}_{2}$ derived from petroleum-based plastics [38-41]. The hydrophilic ISB content can increase the degree of hydrophilicity compared to BPA-based polymers which should increase the affinity towards the polar micropollutants in aqueous solutions. The main aim of this work is to design phosphoryl derivatives polymers as film for the modification of the gold electrodes. The synthesized polymers were fully characterized using NMR spectroscopy, GPC, DSC and ATG and then the analytical performance of the modified electrodes for the detection of $\mathrm{Cd}, \mathrm{Pb}, \mathrm{Ni}$ and $\mathrm{Hg}$ was determined using electrochemical impedance spectroscopy.

\section{Materials and Methods}

\subsection{Reagents and Standards}

The reagents used in the synthesis of monomers, aluminum chloride anhydrous $\left(\mathrm{AlCl}_{3}\right)$, Fluorobenzene (99\%), thiophosphoryl chloride $\left(\mathrm{PSCl}_{3}, 98 \%\right)$, toluene $(99 \%)$ anhydrous potassium carbonate and N,N-dimethylacetamide (DMAc, 99\%) were purchased from Sigma-Aldrich (St. Louis, MO, USA). The reagents used for the polymerization, 2,2-bis(4-hydroxyphenyl)propane (bisphenol A) was recrystallized from toluene and isosorbide was recrystallized from acetone and dried under vacuum. Other solvents were of reagent-grade quality and were used without further purification.

Solutions of metallic ions were prepared from standard solutions for AAS in nitric acid (Sigma-Aldrich). Potassium citrate tribasic monohydrate $(98 \%)$ and ethylenediaminetetraacetic acid (EDTA, $\geq 99 \%$ ) were purchased from Sigma-Aldrich.

\subsection{Monomer Synthesis}

The monomers useful for the polycondensation reactions were obtained in three steps as described afterwards and presented in Figure 1.

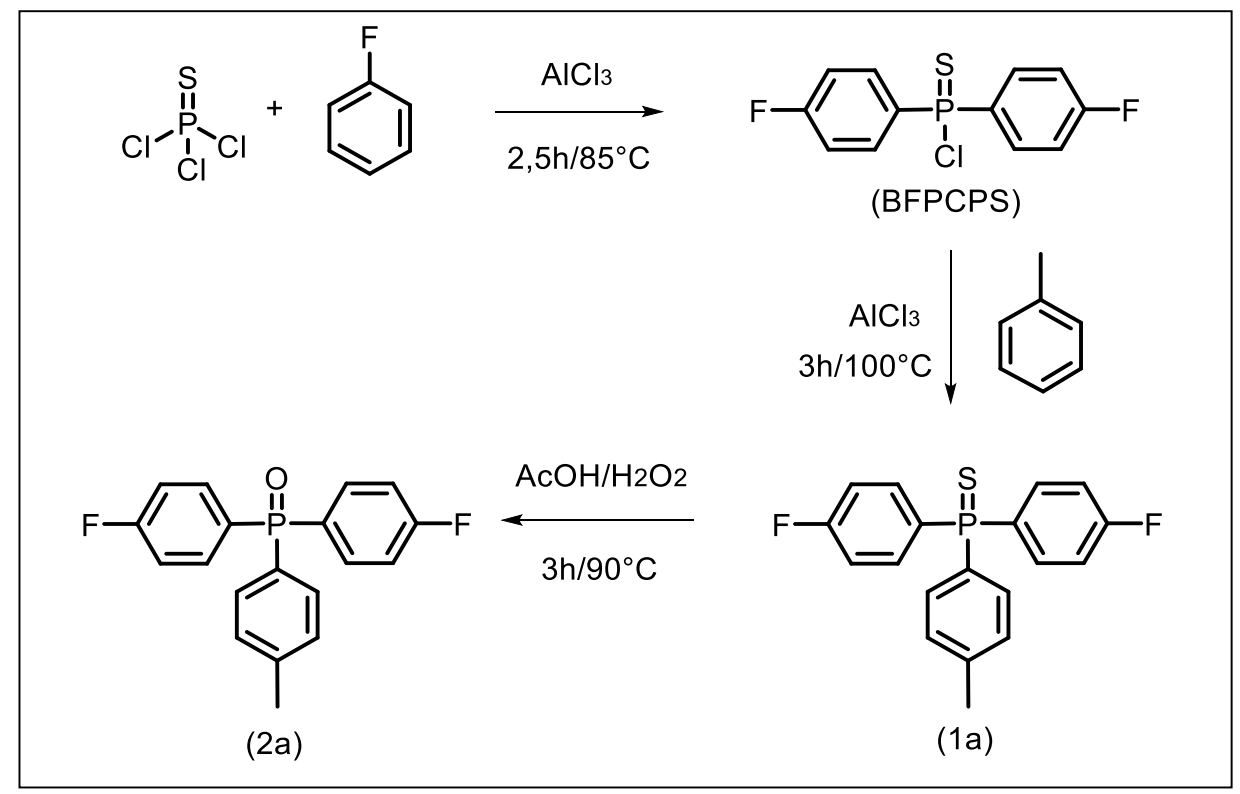

Figure 1. Different steps for the synthesis of the monomers.

\subsubsection{Bis(4-fluorophenyl)chlorophosphine sulfide (BFPCPS)}

Into a $250 \mathrm{~mL}$ two round-bottom flask equipped with a magnetic stirrer, a condenser (the top of condenser was connected by a potassium hydroxide trap to recover the acid) and $\mathrm{N}_{2}$ inlet, were added $\mathrm{AlCl}_{3}(14 \mathrm{~g}, 0.105 \mathrm{~mol}), \mathrm{PSCl}_{3}(11.94 \mathrm{~g}, 0.07 \mathrm{~mol})$, and excess of fluorobenzene ( $\left.26.9 \mathrm{~g}, 0.28 \mathrm{~mol}\right)$, to serve both as reactant and solvent. The solution was stirred magnetically while being heated at $85^{\circ} \mathrm{C}$ to reflux the fluorobenzene for a period of $3 \mathrm{~h}$. Thereafter, $450 \mathrm{~mL}$ of ice water was added to cool the 
solution. Ethyl acetate was added to help the phase separation. Afterwards, the organic phase was separated and subsequently washed three times with water. The organic layer was dried over $\mathrm{Na}_{2} \mathrm{SO}_{4}$ and after filtration, the solvent of the mixture was removed under reduced pressure. The BFPCPS was obtained as a white solid with a yield of $85 \%$. The purification of the BFPCPC was carried out by washing twice with $n$-hexane. Its structure and its purity were checked through NMR spectra.

\subsubsection{Bis(4-fluorophenyl)(4-methylphenyl)phosphine sulfide (1a)}

Into a $250 \mathrm{~mL}$ two neck round-bottom flask equipped with a magnetic stirrer, a condenser (connected by a potassium hydroxide trap) and $\mathrm{N}_{2}$ inlet, were added $\mathrm{AlCI}_{3}(13.84 \mathrm{~g}, 0.104 \mathrm{~mol}$ ), BFPCPS $(10.00 \mathrm{~g}, 0.034 \mathrm{~mol})$, and excess of toluene $(12.75 \mathrm{~g}, 0.138 \mathrm{~mol})$, to serve both as reactant and solvent. The solution was stirred magnetically while being heated at $110{ }^{\circ} \mathrm{C}$ for a period of $3 \mathrm{~h}$. After cooling to room temperature, the reaction mixture was poured in $500 \mathrm{~mL}$ of ice water. Ethyl acetate was added to help the phase separation. The organic phase was dried over $\mathrm{Na}_{2} \mathrm{SO}_{4}$ and, after filtration, the solvent of the mixture was removed under reduced pressure. Then, the obtained solid was washed several times with petroleum ether and dried to give a brown solid with a yield of $65 \%$. The monomer 1 a was purified by recrystallization from cyclohexane.

\subsubsection{Bis(4-fluorophenyl)(4-methylphenyl)phosphine oxide (2a)}

To a three-neck round-bottom flask equipped with a condenser, (5.36 g, $0.155 \mathrm{~mol})$ of (1a) and $17 \mathrm{~mL}$ of acetic acid were added under $\mathrm{N}_{2}$. The temperature was then brought to $90{ }^{\circ} \mathrm{C}$ until the reagent (1a) was totally dissolved. Afterward, (1.67 g, $0.049 \mathrm{~mol})$ of $35 \%$ of $\mathrm{H}_{2} \mathrm{O}_{2}$ were added drop wise, over a period of $20 \mathrm{~min}$ then the mixture was stirred for $4 \mathrm{~h}$. Thereafter, the reactor was allowed to cool to room temperature whereupon the sulfur containing by-product precipitated out. Next, the reaction mixture was filtered over a bed of celite in a Buchner funnel via gravity filtration and washed two times with acetic acid. Then, ethyl acetate was added to help in the phase separation. The aqueous phase was discarded and the organic phase was washed twice with saturated sodium carbonate solution. The organic layer was dried over $\mathrm{Na}_{2} \mathrm{SO}_{4}$ and after the filtration, the solvent was removed under reduced pressure. Finally, the obtained solid was washed several times with petroleum ether and dried to give a solid with a yield of $68 \%$. The monomer $2 a$ was purified by recrystallization from a mixture of ethyl acetate/cyclohexane with a ratio of 10/90 (vol/vol).

\subsection{Synthesis of Polymers}

The typical polymerization procedure for the synthesis of polymers P-P4 (chemical structures are given in Figure 2) was as follows. Isosorbide (1.6415 g, $5 \mathrm{mmol})$ (or BPA (1.1414 g, $5 \mathrm{mmol})$ ), (2a) (1.6415 g, $5 \mathrm{mmol}$ ) (or (1a) $(1.7218 \mathrm{~g}, 5 \mathrm{mmol})$ ), and $\mathrm{K}_{2} \mathrm{CO}_{3}(3.040 \mathrm{~g}, 22 \mathrm{mmol})$ were added to $9.5 \mathrm{~mL}$ of DMAc (20\% solid) and heated at $160{ }^{\circ} \mathrm{C}$ for $24 \mathrm{~h}$, in a two-necked reactor equipped with a $\mathrm{N}_{2}$ inlet and a mechanical stirrer. After cooling, the mixture was poured into water. The precipitated polymer was collected by filtration, washed with water and methanol, and dried under vacuum at $50{ }^{\circ} \mathrm{C}$ for $48 \mathrm{~h}$.

\subsection{Charaterization Methods}

${ }^{1} \mathrm{H},{ }^{19} \mathrm{~F}$, and ${ }^{31} \mathrm{P}$ nuclear magnetic resonance (NMR) spectra were recorded on a Brucker Advance 300 spectrometer (Brucker, Palaiseau, France) operating at the following frequencies of $300 \mathrm{MHz}$ for ${ }^{1} \mathrm{H}, 282 \mathrm{MHz}$ for ${ }^{19} \mathrm{~F}$, and $121 \mathrm{MHz}$ for ${ }^{31} \mathrm{P}$. Tetramethylsilane (TMS), $\mathrm{CFCl}_{3}$, and $85 \% \mathrm{H}_{3} \mathrm{PO}_{4}$ were used as internal standards for ${ }^{1} \mathrm{H},{ }^{19} \mathrm{~F}$ and ${ }^{31} \mathrm{P}$, respectively.

Thermogravimetric analyses (TGA) were performed under nitrogen atmosphere, from room temperature to $500{ }^{\circ} \mathrm{C}$, at a heating rate of $10^{\circ} \mathrm{C} / \mathrm{min}$, using a TA Q50 Instrument (TA Instruments Division de Waters SAS, Guyancourt, France). 


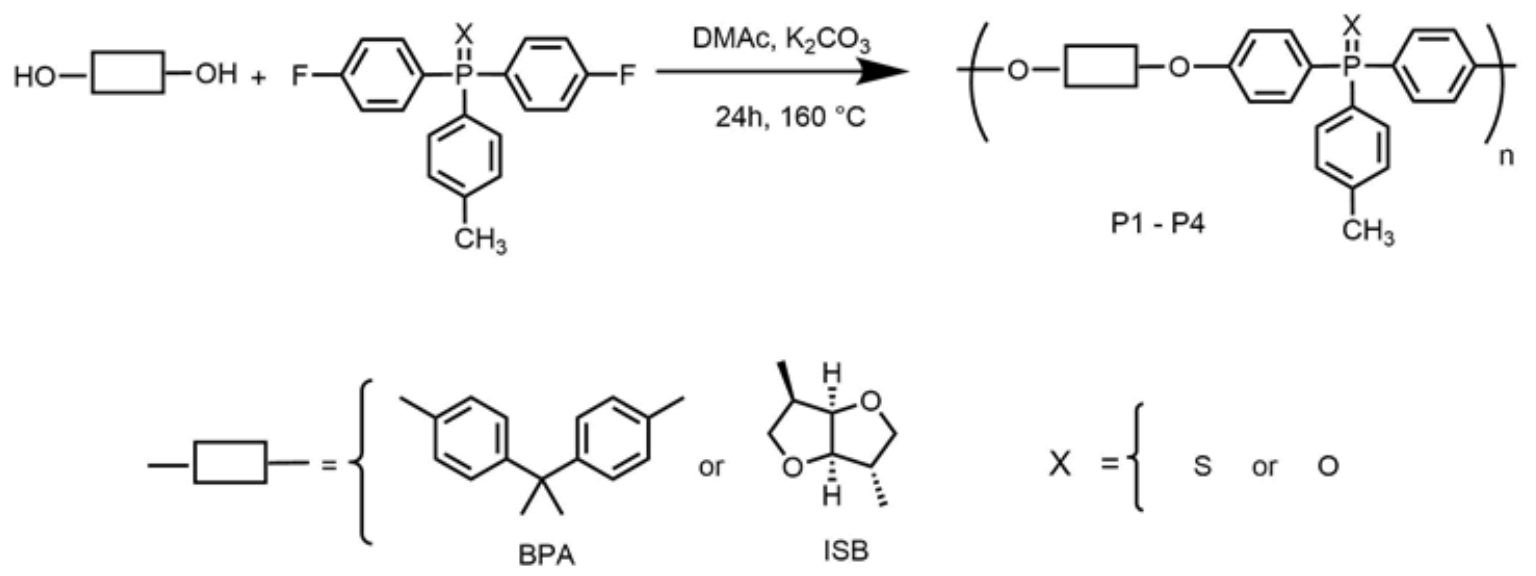

Figure 2. The synthetic routes of the poly(etherphosphine)s polymers P1-P4. (P1 = ISB and $\mathrm{X}=\mathrm{O} / \mathrm{P} 2=\mathrm{ISB}$ and $\mathrm{X}=\mathrm{S} / \mathrm{P} 3=\mathrm{BPA}$ and $\mathrm{X}=\mathrm{O} / \mathrm{P} 4=\mathrm{BPA}$ and $\mathrm{X}=\mathrm{S}$ ).

Polymer glass transition temperatures ( $\mathrm{Tg}$ ) were determined by differential scanning calorimetric (DSC), with a Mettler-Toledo DSC822e equipment (Viroflay, France). Analyses were performed at a heating and cooling rate of $5{ }^{\circ} \mathrm{C} / \mathrm{min}$ from $25^{\circ} \mathrm{C}$ to $300{ }^{\circ} \mathrm{C}$, in an argon atmosphere. The reported values were obtained from the second heat scan by the mid-point method.

Molecular weights were determined by size exclusion chromatography (SEC) and carried out on a system comprising a Shimadzu LC 20 AD pump (Shimadzu, Marne-la-Vallee, France), a Perkin Elmer Series 200 automatic injector (Perkin Elmer, Villebon sur Yvette, France), a Wyatt TREOS 3 angle light scattering detector (Wyatt Technology, Toulouse, France), a Shimadzu RID 10A refractometer and a PL gel $5 \mu \mathrm{m}$ Mixed C ( $300 \times 7.5 \mathrm{~mm}$, polystyrene/divinylbenzene) column. Chloroform was used as eluent. Reported values (number average molar masses $(\mathrm{Mn})$, weight average molar masses $(\mathrm{Mw})$ and chain disparities $(\mathrm{PD})$ were determined from a polystyrene calibration curve.

\subsection{Preparation of Polymer-Modified Gold Electrodes and Impedimetric Measurements}

Gold substrates ( $300 \mathrm{~nm}$ of gold layer/30 nm of titanium layer/300 nm SiO $2 / p$-type $\mathrm{Si} / 300 \mathrm{~nm} \mathrm{SiO} 2$ ) were provided by the French RENATECH network (LAAS, CNRS Toulouse). The gold electrodes were $1.2 \times 1.2 \mathrm{~cm}$ square plates. The gold surface was rinsed with acetone for $15 \mathrm{~min}$, rinsed with ultrapure water then dried under nitrogen flow. Then it was alternately immersed for $2 \mathrm{~min}$ in freshly prepared hot piranha solution, rinsed with ultrapure water, and dried under nitrogen flow. After the surface treatment, $5 \mu \mathrm{L}$ of $1 \mathrm{w} / \mathrm{w} \%$ chloroform solution of P1, P2, P3 or P4 polymer was dropped on the electrode surface and then dried under nitrogen flow. Drop-coating was chosen because spin-coating was not applicable, due to the volatility of chloroform.

Electrochemical measurements were performed in a $5 \mathrm{~cm}^{3}$ Pyrex glass electrochemical cell equipped with the polymer-modified gold electrode $\left(0.07 \mathrm{~cm}^{2}\right.$ active area, defined by an O-ring seal), as a working electrode, a platinum counter-electrode and an $\mathrm{Ag} / \mathrm{AgCl}$ reference electrode. All measurements were carried out at room temperature $\left(23 \pm 3{ }^{\circ} \mathrm{C}\right)$. When the polymer-modified gold electrode was in contact with the $0.1 \mathrm{M}$ potassium citrate solution $(\mathrm{pH} 4.0)$ containing the metallic ions, the measurements were performed after $10 \mathrm{~min}$ of equilibration. Electrochemical impedance spectroscopy (EIS) measurements were operated using a potentiostat-galvanostat Voltalab 80 (Hach, Düsseldorf, Germany). In these experiments, an amplitude of $10 \mathrm{mV}$, with a frequency range of $100 \mathrm{mHz}$ to $100 \mathrm{kHz}$, was superimposed to a dc voltage. The value of the dc voltage was the free potential of the modified electrode in $0.1 \mathrm{M}$ potassium citrate solution at $\mathrm{pH} 4.0$. The real and imaginary impedances were computed and a Nyquist plot was drawn. The impedance values were fitted, using Zview software from Scribner Associates, to a standard Randles equivalent circuit consisting of a parallel combination of a constant phase element (CPE) and a Faradaic impedance $\mathrm{Zf}$ in 
series with the solution resistance (Rs). The faradic impedance is a series combination of polarization resistance $(\mathrm{Rp})$ and the Warburg impedance $(\mathrm{W})$.

The surface topography of the polymer-modified gold electrode was characterized by AFM. The AFM measurements were carried out using an Agilent 5500 AFM (Agilent Technologies, Palo Alto, CA, USA). Silicon tips with a nominal spring constant of $20 \mathrm{~N} \mathrm{~m}^{-1}$ were used in tapping mode at a frequency of $\sim 300 \mathrm{kHz}$.

\section{Results and Discussion}

\subsection{Physicochemical Characterization of the Resulting Polymers P1-P4}

The difluoro aromatic monomers, bis(4-fluorophenyl)(4-methylphenyl)phosphine sulfide (1a) and the bis(4-fluorophenyl)(4-methylphenyl)phosphine oxide (2a) were synthesized according the route described in Figure 2, with satisfactory yields. The bis(4-fluorophenyl)(4-methylphenyl)phosphine sulfide was synthesized via Friedel-Crafts chemistry. This synthesized approach consisted firstly in the preparation of bis(4-fluorophenyl)chlorophosphine sulfide (BFPCPS) and then the electrophilic substitution to the trisubstituted phosphine sulfide (2a). The bis(4-fluorophenyl)(4-methylphenyl)phosphine oxide (2a) was prepared via the oxidation of the prepared phosphine sulfide (1a) in acetic acid with aqueous hydrogen peroxide. Representative NMR data of protons related to the chemical structures of synthesized monomers and polymers are reported in Figure S1. All the synthesized monomers (Figure 1) used for the reactions of polycondensation and resulting polymers $\mathrm{P} 1-\mathrm{P} 4$ (Figure 2) were fully characterized by ${ }^{1} \mathrm{H},{ }^{19} \mathrm{~F}$ and ${ }^{31} \mathrm{P} \mathrm{NMR}$, the results of their characterization positively confirms the proposed structure with high purity (Figure S1).

The obtained monomers were incorporated in poly(etherphosphine) structures by aromatic nucleophilic substitution (Figure 2). Typically, the polymerization was performed by condensation of the different monomers (Isosorbide, bisphenol A (1a) and (2a)) in a polar aprotic solvent (DMAc), in the presence of $\mathrm{K}_{2} \mathrm{CO}_{3}$, at $160^{\circ} \mathrm{C}$. At the end of the polymerization reaction, the polymers were isolated by precipitation in water and dried in vacuum during $48 \mathrm{~h}$ at $50^{\circ} \mathrm{C}$.

As shown in Table 1, the yields of all the polymers were more than $78 \%$. The number average molecular weight (Mn) of the synthesized polymers is between 1967 and $4252 \mathrm{Da}$ and the dispersity index (PD) ranges from 2.02 to 2.86 . These polycondensates possess polymerization degrees in the range of 5-10 therefore they can be considering as oligomers.

Table 1. Yields, thermal behaviors and molecular weights of resulting polymers P1-P4.

\begin{tabular}{ccccccc}
\hline Ref. Polymer & $\begin{array}{c}\text { Yield }^{\mathbf{a})} \\
(\mathbf{\%})\end{array}$ & $\begin{array}{c}\mathbf{T g}^{\mathbf{b})} \\
\left({ }^{\circ} \mathbf{C}\right)\end{array}$ & $\begin{array}{c}\mathbf{T d}_{\mathbf{5}}{ }^{\mathbf{c})} \\
\left({ }^{\circ} \mathbf{C}\right)\end{array}$ & $\begin{array}{c}\mathbf{M}_{\mathbf{n}}{ }^{\mathbf{d})} \\
(\mathbf{D a})\end{array}$ & $\begin{array}{c}\mathbf{M}_{\mathbf{w}}{ }^{\mathbf{d})} \\
(\mathbf{D a})\end{array}$ & PD $^{\mathrm{d})}$ \\
\hline P1 & 80 & 202 & 408 & 1967 & 3826 & 2.72 \\
\hline P2 & 82 & 196 & 403 & 4252 & 8575 & 2.02 \\
\hline P3 & 78 & 184 & 431 & 2856 & 8034 & 2.86 \\
\hline P4 & 89 & 185 & 431 & 3508 & 9798 & 2.79 \\
\hline
\end{tabular}

a) After precipitation into water and washing with methanol. ${ }^{\text {b) }}$ Determined by DSC with a heating rate of $10^{\circ} \mathrm{C} / \mathrm{min}$ under an argon flow of $(50 \mathrm{~mL} / \mathrm{min}) .{ }^{\text {c) }}$ Temperature at which $5 \%$ of weight loss was observed in the TGA traces recorded at $10^{\circ} \mathrm{C}$. d) Number and weight-averaged molecular weights and polydispersity (PD) determined by GPC in $\mathrm{CHCl}_{3}$ (calibrated with polystyrene).

The chemical composition of the prepared poly(etherphosphine) was ascertained by NMR spectroscopy. A detailed description of the NMR data recorded from poly(etherphosphine) sulphides and oxides are given in Figure $\mathrm{S} 1$ and the ${ }^{1} \mathrm{H}$ and ${ }^{31} \mathrm{P}$ NMR spectra of the bio-based poly(etherphosphine) oxide P1 are shown in Figure S2.

The spectrum exhibits the characteristic protons of isosorbide (H1-H6) and of the monomer 2a (H7-H11). Furthermore, spectral analyses show the presence of peaks with low intensity corresponding 
to protons at the end groups of isosorbide $\left(\mathrm{H} 4^{*}, \mathrm{H} 2^{*}, \mathrm{H} 1^{*}, \mathrm{H} 6^{*}\right)$ and of $(2 \mathrm{a})\left(\mathrm{H} 7^{*}\right.$ and $\left.\mathrm{H} 8^{*}\right)$. For the phosphorus NMR analysis, the spectrum of P1 presents a single peak at $28 \mathrm{ppm}$, which is assigned to the phosphorus nucleus of phosphine oxide group $(\mathrm{PO}(\mathrm{R}) 3)$.

The thermal properties of the polymers were investigated by thermogravimetric analyses (TGA) and differential scanning calorimetric (DSC). The study of the thermal properties of polymers P1-P4 has, at least, double objectives: (i) this technique is one of the most important analytical techniques for the physico-chemical characterization of polymers whatever their molecular weights; (ii) these polymers can be used later as reversible adsorption phases for volatile pollutants in water with a possible combination with organo-mineral substrates for SPE, SPME or SBSE applications (work under progress).

The $5 \%$ weight-loss temperatures $\left(\mathrm{Td}_{5 \%}\right)$ of the petro-based poly(arylene etherphosphine oxide) (P3) was observed to be higher than $430{ }^{\circ} \mathrm{C}$ under nitrogen (Table 1 and Figure S2). This $\operatorname{Td}_{5 \%}$ is higher than that of the bio-based poly(arylene phosphine oxide) $\left(\mathrm{P} 2,408^{\circ} \mathrm{C}\right)$. In addition, the petro-based poly(arylene ether phosphine sulfide) (P4) also has excellent stability compared to the bio-based polymers. Despite this, the $\mathrm{Td}_{5 \%}$ of $\mathrm{P} 1$ and $\mathrm{P} 2$ were higher than $400{ }^{\circ} \mathrm{C}$ in nitrogen, still demonstrating excellent thermal stability.

From the results given in Figure S3, we can observe that polymers based on isosorbide (P1 and P2) showed higher Tg values, compared to those obtained from bisphenol A (P3 and P4). In a previous work, we have obtained similar behavior for poly(ether-sulfone) from isosorbide and bisphenol A [42]. Not a big difference on $\mathrm{Tg}$ values was observed between oxide or sulfide functions.

\subsection{Detection of $\mathrm{Pb}^{2+}$ Ion by EIS Measurements}

The morphology of the polymer-modified electrode was characterized by AFM. The AFM image for polymer P1, presented in Figure S4, shows that the dip-coated polymer film is quite homogeneous and rather smooth, a roughness of less than $3 \mathrm{~nm}$ is observed. The thickness of the polymers was determined by AFM, after a groove was created in the polymer film. The found thickness was $2 \pm 0.2 \mu \mathrm{m}$ for the four polymers.

1. Comparative sensitivity of (P1-P4) polymers modified gold electrode

The impedance of the polymer-modified gold electrode/electrolyte interface decreased when the concentration of lead increased in the acetate solution. The response of the sensor was characterized by the value of the polarization resistance $\mathrm{Rp}$ that decreased when the lead concentration increased. In order to obtain the calibration curves, we have plotted the relative variation of the polarization resistance $\Delta \mathrm{Rp} / \mathrm{R} 0$ versus the co-logarithm concentration of $\mathrm{Pb}^{2+}$ (Figure 3). In the previous formula $\Delta \mathrm{Rp} / \mathrm{R} 0, \mathrm{R} 0$ is the polarization resistance in presence of the acetate solution and $\Delta \mathrm{Rp}$ is the difference between $\mathrm{Rp}$ in the presence of different concentrations of lead ion and R0.

The linear range, the limits of detection and the sensitivities obtained for the different polymers are reported in Table 2. The sensitivities are the slopes of the calibration curves: $\Delta \mathrm{Rp} / \mathrm{R} 0=\mathrm{f}(-\log [\mathrm{Pb}]$. Both parameters being without units, these slopes are without unit. The comparison of the data reveals that the poly(etherphosphine) oxide based on isosorbide (P1) as modifier of the electrode gives the better results in comparison to $\mathrm{P} 2, \mathrm{P} 3$ and $\mathrm{P} 4$. The ratio of the sensitivities for the different polymers are the following ones: $\mathrm{P} 1$ is 2.4 times more sensitive than P2, 1.8 more sensitive than P3 and 2.5 times more sensitive than P4. This sensitivity of P1, obtained from isosorbide, can be related to the fact that it is the most hydrophilic polymer when compared to P3 due to the presence of oxygen atoms in the chemical structure of the biobased diol. A similar study was performed on partially bio-based polymers derived from isosorbide and petroleum-based polymers derived from bisphenol A, using the contact angle measurements [43]. We then demonstrated that more hydrophilic the polymer is, higher the affinity for the metallic ions is. In fact, the contact angle measurement shows that the presence of isosorbide in the chemical structure of polymers increase the surface hydrophilicity and in contrary polymers containing BPA is more hydrophobic. Likewise, the $\mathrm{P}=\mathrm{S}$ groups in polymer chain can make the polymer more hydrophobic than polymers containing the $\mathrm{P}=\mathrm{O}$ groups in the main chain, 
thereby increasing the hydrophobicity of the polymers and thus decreasing the probability of stronger interaction with the lead ions.

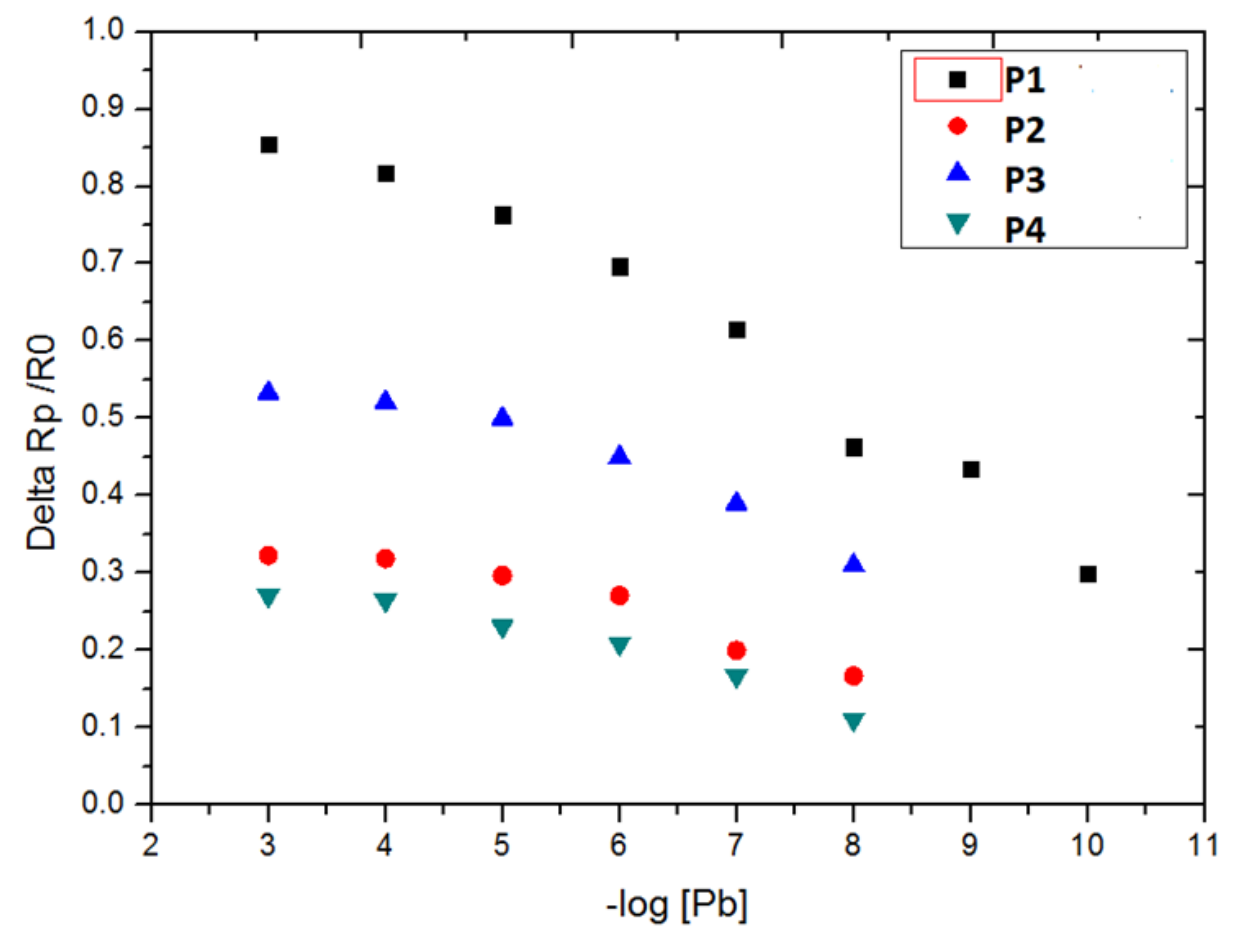

Figure 3. Relative variation of the polarization resistance of the polymer-modified gold electrode interface as a function of $-\log$ concentration of $\mathrm{Pb}^{2+}$ ion $(\mathrm{g} / \mathrm{L})$.

Table 2. Comparative study: responses of sensors based on $\mathrm{P} 1-\mathrm{P} 4$ polymers for the $\mathrm{Pb}^{2+}$ ion.

\begin{tabular}{cccc}
\hline Sensing Polymers Ref. & Sensitivity & $\begin{array}{c}\text { LOD } \\
{[\mathrm{g} / \mathrm{L}]}\end{array}$ & $\begin{array}{c}\text { Linear Range } \\
{[\mathrm{g} / \mathrm{L}]}\end{array}$ \\
\hline P1 & $80.7 \pm 2.0$ & $10^{-10}$ & {$\left[10^{-10}-10^{-3}\right]$} \\
\hline P2 & $33.2 \pm 0.8$ & $10^{-8}$ & {$\left[10^{-8}-10^{-5}\right]$} \\
\hline P3 & $44.5 \pm 1.1$ & $10^{-8}$ & {$\left[10^{-8}-10^{-5}\right]$} \\
\hline P4 & $31.9 \pm 0.8$ & $10^{-8}$ & {$\left[10^{-8}-10^{-5}\right]$} \\
\hline
\end{tabular}

The detection limit obtained with P1 is $10^{-10} \mathrm{~g} / \mathrm{L}$ or $0.5 \mathrm{pM}$. This detection limit is $10^{4}$ times lower than that obtained by anodic stripping voltammetry on BDD, $5.5 \mathrm{nM}$ [15] and that obtained by potentiometry, $4 \mathrm{nM}$ [21]. The measurements were performed with three different electrodes and the RSD was $2.5 \%$. The value of RSD corresponds to the size of the symbols used in Figure 3.

2. Selectivity study of polymer (P1) modified gold electrode versus $\mathrm{Pb}^{2+}$ ion

In order to investigate the sensitivity of the chemical sensor based on polymer P1 different concentrations of the four metallic ions of the Water Framework Directive: $\mathrm{Pb}^{2+}, \mathrm{Ni}^{2+}, \mathrm{Hg}^{2+}$ and $\mathrm{Cd}^{2+}$ were added to the citrate solution. Each metal was separately studied. The calibration for each metallic ion is presented in Figure 4 The results obtained for lead ion are the same than those presented in Figure 3.

The linear range, the limits of detection and the sensitivities obtained for the different metallic ions are reported in Table 3. 


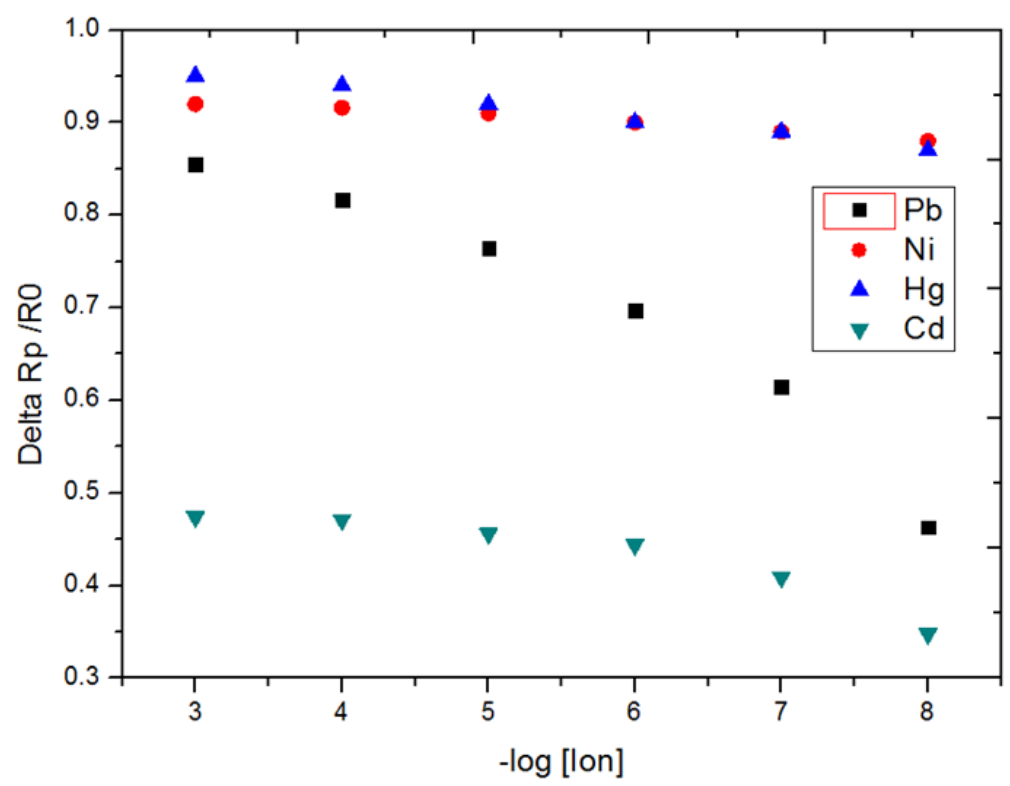

Figure 4. Relative variation of the polarization resistance of the P1 polymer-modified gold electrode interface as a function of $-\log$ concentration [Ion] $\left(\mathrm{Pb}^{2+}, \mathrm{Ni}^{2+}, \mathrm{Hg}^{2+}\right.$ and $\mathrm{Cd}^{2+}$ ions).

Table 3. Comparative study: responses of sensors based on polymer $\mathrm{P} 1$ for the different ions $\mathrm{Pb}^{2+}$, $\mathrm{Hg}^{2+}, \mathrm{Ni}^{2+}$ and $\mathrm{Cd}^{2+}$.

\begin{tabular}{cccc}
\hline Ion & Sensitivity & $\begin{array}{c}\text { LOD } \\
{[\mathrm{g} / \mathrm{L}]}\end{array}$ & $\begin{array}{c}\text { Linear Range } \\
{[\mathrm{g} / \mathrm{L}]}\end{array}$ \\
\hline $\mathrm{Pb}^{2+}$ & $80.7 \pm 2.0$ & $10^{-10}$ & {$\left[10^{-10}-10^{-3}\right]$} \\
\hline $\mathrm{Hg}^{2+}$ & $16.3 \pm 0.4$ & $10^{-8}$ & {$\left[10^{-10}-10^{-5}\right]$} \\
\hline $\mathrm{Ni}^{2+}$ & $10.0 \pm 0.2$ & $10^{-8}$ & {$\left[10^{-10}-10^{-5}\right]$} \\
\hline $\mathrm{Cd}^{2+}$ & $35.9 \pm 0.9$ & $10^{-8}$ & {$\left[10^{-10}-10^{-5}\right]$} \\
\hline
\end{tabular}

The measurements were performed with three different electrodes and the RSD was $2.5 \%$. The value of RSD corresponds to the size of the symbols used in Figure 4.

As it can be concluded from the obtained results, a good response for the detection of the four metals is revealed, principally for $\mathrm{Pb}^{2+}$. The ratio of the sensitivities for the different metallic ions are the following ones: the sensitivity for $\mathrm{Pb}^{2+}$ is 4.9 times higher than that of $\mathrm{Hg}^{2+}, 8$ times higher than that of $\mathrm{Ni}^{2+}$ and 2.2 times higher than that of $\mathrm{Cd}^{2+}$. Detection limit for $\mathrm{Pb}^{2+}$ is 100 times lower than that of the other metallic ions. This phenomenon can be explained by the relatively high electronegativity of $\mathrm{Pb}$ ion compared to mercury, cadmium and nickel.

3. Reusability and shelf lifetime of the P1 modified gold electrode

The original value of impedance is restored after washing with a 0.1 M EDTA solution, due to the desorption of $\mathrm{Pb}^{2+}$. Then the adsorption of $\mathrm{Pb}^{2+}$ is studied and the same calibration was obtained. A variation of $5 \%$ in the sensitivity was observed after 10 adsorption-desorption cycles, every week, as presented in Figure S5. After one month of storage, a variation of less than 3\% in the sensitivity was observed

\section{Conclusions}

In this work, impedimetric sensors were developed for the detection of the four WFD heavy metals $\mathrm{Pb}^{2+}, \mathrm{Cd}^{2+}, \mathrm{Hg}^{2+}$ and $\mathrm{Ni}^{2+}$, by the modification of a gold electrode with four polyphosphine polymers. The bio-based poly(etherphosphine) oxide (P1) modified gold electrode showed better analytical performance than petrochemical-based oxide. A detection limit of $10^{-10} \mathrm{~g} / \mathrm{L}$ or $0.5 \mathrm{pM}$ which 
is $10^{4}$ times lower than that of the anodic stripping voltammetric and the potentiometric sensors. A reversibility is obtained through its rinsing with an EDTA solution, allowing an effective reusability. This novel impedimetric sensor is a good candidate for on-line monitoring of $\mathrm{Pb}^{2+}$ during the treatment of wastewater generated by industrial activities.

Supplementary Materials: The following are available online at http://www.mdpi.com/2227-9040/8/2/34/s1, Figure S1: Representative NMR data of protons related to the chemical structures of synthesized monomers and polymers, Figure S2: TGA thermograms of resulting polymers P1-P4 under nitrogen, Figure S3: DSC heating curves of resulting polymers P1-P4 under nitrogen, Figure S4: AFM image of the P1-modified gold electrode, Figure S5: Relative variation of the $\mathrm{Pb}^{2+}$ signal after one adsorption-desorption cycle every week.

Author Contributions: Conceptualization, R.M. and H.C.; methodology, R.S.; validation, I.R.; investigation, T.C. and P.S.-M.; writing-original draft preparation, S.C. and H.A.; writing-review and editing, N.J.-R.; funding acquisition, A.E. and M.H. All authors have read and agreed to the published version of the manuscript.

Funding: We would like to acknowledge the Financial support of CAMPUS-FRANCE and Institut Français of the French Embassy in Tunisia (Pierre Durand De Ramefort) for the SSHN grant, of the High Ministry of Education and Research in Tunisia for doctoral grant and European Commission for TUNWIN project Grant \#952306.

Conflicts of Interest: The authors declare no conflict of interest.

\section{References}

1. Cheng, S. Heavy metal pollution in China: Origin, pattern and control. Environ. Sci. Pollut. Res. 2003, 10, 192-198. [CrossRef] [PubMed]

2. Cheng, $\mathrm{H}$.; $\mathrm{Hu}, \mathrm{Y}$. Lead $(\mathrm{Pb})$ isotopic fingerprinting and its applications in lead pollution studies in China: A review. Environ. Pollut. 2010, 158, 1134-1146. [CrossRef] [PubMed]

3. Diarra, I.; Prasad, S. The current state of heavy metal pollution in Pacific Island Countries: A review. Appl. Spectrosc. Rev. 2020. [CrossRef]

4. Rai, P.K.; Lee, S.S.; Zhang, M.; Tsang, Y.F.; Kim, K.-H. Heavy Metals in Food Crops: Health Risks, Fate, Mechanisms, and Management. Environ. Int. 2019, 125, 365-385. [CrossRef]

5. Jaishankar, M.; Tseten, T.; Anbalagan, N.; Mathew, B.B.; Beeregowda, K.N. Toxicity, mechanism and health effects of some heavy metals. Interdiscip. Toxicol. 2014, 7, 60-72. [CrossRef]

6. Tchounwou, P.B.; Yedjou, C.G.; Patlolla, A.K.; Sutton, D.J. Heavy Metals Toxicity and the Environment. Exp. Suppl. 2012, 101, 133-164.

7. Yoshinaga, M.; Ninomiya, H.; Al Hossain, M.M.A.; Sudo, M.; Akhand, A.A.; Ahsan, N.; Alim, M.A.; Khalequzzaman, M.; Iida, M.; Yajima, I.; et al. A Comprehensive Study Including Monitoring, Assessment of Health Effects and Development of a Remediation Method for Chromium Pollution. Chemosphere 2018, 201, 667-675. [CrossRef]

8. Commission Implementaing Decision (EU) 2018/840 of 5 June 2018 establishing a watch list of substances for Union-wide monitoring in the field of water policy pursuant to Directive 2008/105/EC of the European Parliament and of the Council and repealing Commission Implementing Decision (EU) 2015/495. Available online: https://eur-lex.europa.eu/legal-content/EN/TXT/PDF/?uri=CELEX:32018D0840\&from=fr (accessed on 10 May 2020).

9. Trindade, A.S.N.; Dantas, A.F.; Lima, D.C.; Ferreira, S.L.C.; Teixeira, L.S.G. Multivariate optimization of ultrasound-assisted extraction for determination of $\mathrm{Cu}, \mathrm{Fe}, \mathrm{Ni}$ and $\mathrm{Zn}$ in vegetable oils by high-resolution continuum source atomic absorption spectrometry. Food Chem. 2015, 185, 145-150. [CrossRef]

10. Sitko, R.; Janik, P.; Zawisza, B.; Talik, E.; Margui, E.; Queralt, I. Green approach for ultratrace determination of divalent metal ions and arsenic species using total-reflection X-ray fluorescence spectrometry and mercapto-modified graphene oxide nanosheets as a novel adsorbent. Anal. Chem. 2015, 87, 3535-3542. [CrossRef] [PubMed]

11. Paquin, F.; Rivnay, J.; Salleo, A.; Stingelin, N.; Silva, C. Multi-Phase Semicrystalline microstructures drive exciton dissociation in neat plastic semiconductors. J. Mater. Chem. C 2015, 3, 10715-10722. [CrossRef]

12. Steinnes, E. Atmospheric deposition of heavy metals in Norway studied by the analysis of moss samples using neutron activation analysis and atomic absorption spectrometry. J. Radioanal. Chem. 1980, 58, 387-391. [CrossRef] 
13. Cui, C.; He, M.; Hu, B. Membrane solid phase microextraction with alumina hollow fiber on line coupled with ICP-OES for the determination of trace copper, manganese and nickel in environmental water samples. J. Hazard. Mater. 2011, 187, 379-385. [CrossRef] [PubMed]

14. Sbartai, A.; Namour, P.; Errachid, A.; Krejci, J.; Sejnohova, R.; Renaud, L.; Hamlaoui, M.L.; Loir, A.S.; Garrelie, F.; Donnet, C.; et al. Electrochemical boron-doped diamond film microcells micromachined with femtosecond laser: Application to the determination of Water Framework Directive metals. Anal. Chem. 2012, 84, 4805-4811. [CrossRef] [PubMed]

15. Sbartai, A.; Namour, P.; Barbier, F.; Krejci, J.; Kunceriva, R.; Krejci, T.; Nedela, V.; Sobota, J.; Jaffrezic-Renault, N. Electrochemical performances of diamond like carbon for $\mathrm{Pb}$ (II) detection in tap water using differential pulse anodic stripping voltammetry technique. Sens. Lett. 2013, 11, 1524-1529. [CrossRef]

16. Ben Mefteh, W.; Touzi, H.; Chevalier, Y.; Ben Ouada, H.; Othmane, A.; Kalfat, R.; Jaffrezic Renault, N. Comparison of polysiloxane films substituted by undecenyl-cyclam and by naphthyl-cyclam for the design of ISFET devices sensitive to Fe3+ ions. Sens. Actuators B Chem. 2014, 204, 723-733. [CrossRef]

17. Ben Mefteh, W.; Chevalier, Y.; Bala, C.; Jaffrezic-Renault, N. Voltammetric Detection of Copper Ions on a Gold Electrode Modified with a N-methyl-2-naphthyl-cyclam film. Anal. Lett. 2018, 51, 971-982. [CrossRef]

18. Ben Mefteh, W.; Touzi, H.; Chevalier, Y.; Bessueille, F.; Kalfat, R.; Jaffrezic Renault, N. Gold electrodes functionalized by methyl-naphthyl substituted cyclam films for the detection of metal ions. Sens. Actuators B Chem. 2015, 213, 334-342. [CrossRef]

19. Zazoua, A.; Morakchi, K.; Kherrat, R.; Samar, M.H.; Errachid, A.; Jaffrezic-Renault, N.; Boubellout, R. Electrochemical characterization of an EIS sensor functionalized with a TOPO doped polymeric layer for Cr(VI) detection. ITBM-RBM 2008, 29, 187-191. [CrossRef]

20. Yaftian, M.R.; Parinejad, M.; Matt, D. A lead-selective membrane electrode based upon a phosphorylated hexahomotrioxacalix[3]arene. J. Chin. Chem. Soc. 2007, 54, 1535-1542. [CrossRef]

21. Corbridge, D.E.C. Phosphorus: Chemistry, Biochemistry and Technology, 6th ed.; CRC Press: New York, NY, USA, 2013; pp. 1139-1164.

22. Mayer, H.A.; Kaska, W.C. Stereochemical control of transition metal complexes by polyphosphine ligands. Chem. Rev. 1994, 94, 1239-1272. [CrossRef]

23. Iliescu, S.; Zubizarreta, L.; Plesu, N.; Macarie, L.; Popa, A.; Ilia, G. Polymers containing phosphorus groups and polyethers: From synthesis to application. Chem. Cent. J. 2012, 6, 1-13. [CrossRef] [PubMed]

24. Monge, S.; Canniccioni, B.; Graillot, A.; Robin, J.J. Phosphorus-containing polymers a great opportunity for the biomedical field. Biomacromolecules 2011, 12, 1973-1982. [CrossRef] [PubMed]

25. Ren, H.; Sun, J.; Wu, B.; Zhou, Q. Synthesis and properties of a phosphorus-containing flame retardant epoxy resin based on bis-phenoxy (3-hydroxy) phenyl phosphine oxide. Polym. Degrad. Stab. 2007, 92, 956-961. [CrossRef]

26. Petreus, O.; Vlad-Bubulac, T.; Hamciuc, C. Synthesis and characterization of new polyesters with enhanced phosphorus content. Eur. Polym. J. 2005, 41, 2663-2670. [CrossRef]

27. Chang, Y.L.; Wang, Y.Z.; Ban, D.M.; Yang, B.; Zhao, G.M. A Novel phosphorus-containing polymer as a highly effective flame retardant. Macromol. Mater. Eng. 2004, 289, 703-707. [CrossRef]

28. Chauveau, E.; Marestin, C.; Mercier, R.; Brunaux, A.; Martin, V.; Nogueira, R.P.; Percheron, A.; Roche, V.; Waton, H. Phosphonic acid-containing polysulfones as anticorrosive layers. J. Appl. Polym. Sci. 2015, 132, 1-9. [CrossRef]

29. Biles, J.E.; McNeal, T.P.; Begley, T.H.; Hollifield, H.C. Determination of bisphenol-A in reusable polycarbonate food-contact plastics and migration to food-simulating liquids. J. Agric. Food Chem. 1997, 45, 3541-3544. [CrossRef]

30. Hoekstra, E.J.; Simoneau, C. Release of bisphenol A from polycarbonate-A review. Crit. Rev. Food Sci. Nutr. 2013, 53, 386-402. [CrossRef]

31. Plazek, D.J.; Choy, I.C. The physical properties of bisphenol-A-based epoxy resins during and after curing. II. Creep behaviour above and below the glass transition temperature. J. Polym. Sci. Part B Polym. Phys. 1989, 27, 307-324. [CrossRef]

32. Laskoski, M.; Dominguez, D.D.; Keller, T.M. Synthesis and properties of a bisphenol a based phthalonitrile resin. J. Polym. Sci. Part A Polym. Chem. 2005, 43, 4136-4143. [CrossRef]

33. Ben Abderrazak, H.; Fildier, A.; Ben Romdhane, H.; Chatti, S.; Kricheldorf, H.R. Synthesis of new poly(ether ketone)s derived from biobased diols. Macromol. Chem. Phys. 2013, 214, 1423-1433. [CrossRef] 
34. Chatti, S.; Hani, M.A.; Bornhorst, K.; Kricheldorf, H.R. Poly(ether sulfone) of isosorbide, isomannide and isoidide. High Perform. Polym. 2009, 21, 105-118. [CrossRef]

35. Kricheldorf, H.R.; Chatti, S.; Schwarz, G.; Krüger, R.P. Macrocycles 27: Cyclic aliphatic polyesters of isosorbide. J. Polym. Sci. Part A Polym. Chem. 2003, 41, 3414-3424. [CrossRef]

36. Hani, M.; Chatti, S.; Kricheldorf, H.R.; Zarrouk, H. Polycondensation of isosorbide and various diols by means of diphosgene characterization by a combination of MALDI and NMR. Recent Res. Dev. Org. Chem. 2007, 661, 1-11.

37. Besse, V.; Auvergne, R.; Carlotti, S.; Boutevin, G.; Otazaghine, B.; Caillol, S.; Pascault, J.P.; Boutevin, B. Synthesis of isosorbide-based polyurethanes: An isocyanate free method. React. Funct. Polym. 2013, 73, 588-594. [CrossRef]

38. Nelson, A.M.; Long, T.E. A Perspective on emerging polymer technologies for bisphenol-A replacement. Polym. Int. 2012, 61, 1485-1491. [CrossRef]

39. Fenouillot, F.; Rousseau, A.; Colomines, G.; Saint-Loup, R.; Pascault, J. Progress in polymer science (isosorbide, isomannide and isoidide): A review. Prog. Polym. Sci. 2010, 35, 578-622. [CrossRef]

40. Feng, X.; East, A.J.; Hammond, W.B.; Zhang, Y.; Jaffe, M. Overview of advances in sugar-based polymers. Polym. Adv. Technol. 2011, 22, 139-150. [CrossRef]

41. Rose, M.; Palkovits, R. Isosorbide as a renewable platform chemical for versatile applications-Quo Vadis? ChemSusChem 2012, 5, 167-176. [CrossRef]

42. Belgacem, C.; Medimagh, R.; Kricheldorf, H.; Ben Romdhane, H.; Chatti, S. Copolyethersulfones of 1,4:3,6-dianhydrohexitols and bisphenol A. Des. Monomers Polym. 2016, 19, 248-255. [CrossRef]

43. Gomri, M.; Abderrazak, H.; Souissi, R.; Saint-Martin, P.; Casabianca, H.; Chatti, S.; Mercier, R.; Errachid, A.; Jaffrezic-Renault, N. Combination of partially biosourced poly(ether-pyridine)s films and gold electrodes for the detection of metal ions. under review. 